AGH DRILLING, OIL, GAS • Vol. $30 \cdot$ No. $1 \cdot 2013$

http://dx.doi.org/10.7494/drill.2013.30.1.37

\author{
Kashy Aminian*, Samuel Ameri*
}

\title{
ANALYSIS OF PRODUCTION DATA \\ FROM HYDRAULICALLY FRACTURED HORIZONTAL WELLS IN MARCELLUS SHALE
}

\section{INTRODUCTION}

Unconventional reservoirs play enormous role in hydrocarbon production in the United States. Marcellus Shale, that spans the majority of the Appalachian Basin, has shown notable promise in the past few years. Marcellus shale is expected to be a key contributor to the natural gas supply of the United States. Shale gas reservoirs differ from conventional reservoirs in that economic production can be only achieved by massive stimulation treatments because of the ultra-low permeability of the rock. Although both vertical and horizontal completions can be used, horizontal wells are considered to be more cost effective in achieving commercial production. The limited field experience with multiple hydraulic fractures in horizontal wells indicates that significant increase in initial production can be achieved as the number of hydraulic fractures is increased. However, the production performance, particularly over longer time periods, is not well established. The objective of this study was to develop a basic understanding of the production performance of horizontal wells with multiple hydraulic fractures in ultra-low permeability formations.

\section{BACKGROUND}

Shale, an organic-rich formation, is the source rock as well as the reservoir. The gas is stored in the limited pore space of these rocks and a sizeable fraction of the gas in place may be adsorbed on the organic material (Cipolla et al. 2009a). Shale is a complicated, naturally-fractured reservoir with ultra-low matrix permeability. However, it is believed that

* West Virginia University, Petroleum \& Natural Gas Engineering Department, Morgantown, WV, USA 
natural fractures are mineralized and do not contribute to well productivity unless they are stimulated (Cipolla et al. 2009b). The key to maximizing gas production in ultra-low permeability reservoirs is the development of an interconnected fracture system through effective simulation treatment. The main objective of stimulation treatments is to obtain a large, highly fractured network that can produce from the ultra-low permeability rock. This is commonly accomplished through the use of horizontal wells fractured in multiple stages. Large water-fracs with light proppant are currently being used with good success in many areas (Warpinski et al. 2008).

Unconventional reservoirs such as Marcellus shale are often characterized by dual porosity model (Warren \& Root, 1962). In dual porosity reservoirs, fluid exists in two interconnected systems namely matrix and fissure (naturally occurring fractures). There is a convoluted interaction between the fissures and rock matrix. The matrix (primary porosity) has very low permeability but contains most of the fluid in the system. However, the fissures (secondary porosity) have greater permeability and fluid flow to the wells only occurs through the secondary porosity system. Both hydraulic fractures and natural fractures play significant roles in well performance in low permeability reservoirs. Rosa and Carvalho (1988) were the first to extend the horizontal well solutions to dual porosity systems. Lu et al. (2009) concluded that there were a number of flow regimes present and one or more could be masked or missing depending on reservoir parameters. The flow regimes include the early radial flow (in vertical direction) and it has short duration in thin or high vertical permeability reservoirs. The next flow regimes is known as intermediate linear flow regime and is developed because the length of horizontal well is often much greater than the formation thickness. Subsequently, the transition period becomes dominant, and finally late radial flow period is observed. Ozkan et al. (2009) and Brown et al. (2009) introduced the concept of trilinear flow for hydraulically fracture horizontal wells. They indicated that the contribution of micro-darcy formation beyond the stimulated volume is negligible and flow is mainly linear perpendicular to the hydraulic fracture. The trilinear flow couples three linear flow regions including the hydraulic fracture, the inner area between the fractures, and the area beyond the tip of the fracture. Belyadi et al. (2010) investigated the flow regimes for hydraulically fractured horizontal wells in ultra-low permeability formations. They observed three separate flow regimes including the initial radial-fracture storage flow, the linear flow, and the boundary effected flow. They concluded that as the number of frac stages increases, the duration linear flow decreases and the boundary effected flow starts earlier. They also confirm the presence of the late linear flow (or trilinear flow) for the cases where the drainage area extended beyond the tip of the hydraulic fractures. However, the distinction between the two linear flow regimes may be difficult.

\section{OBJECTIVE AND METHODOLOGY}

The objective of this study was to develop an understanding of the long term production performance of horizontal wells with multiple hydraulic fractures in ultra-low perme- 
ability formations such as Marcellus shale. Specifically, the methodology consisted of the following steps as described below:

\section{Base Model Development}

Based on our previous investigations (Belyadi A. et al. 2010, Belyadi H. 2011, and Belyadi, A. et al. 2012), a multi-layer, dual porosity model with adsorbed gas was employed as the base model for the simulation runs. A commercial reservoir simulator was used to model a horizontal well with multiple hydraulic fractures in the base model.The basic model parameters were established based on the available field information as well as the results of the history matching the production data from Marcellus Shale wells (Belyadi H. 2011). Figure 1 illustrates the results of a typical history match for a Marcellus Shale horizontal well in West Virginia. Table 1 summarizes the basic model parameters used in this study. The model was utilized to generate the production profile with a constant wellbore pressure for a 30-year period for all the simulation runs.

Our previous investigations (Belyadi A. et al. 2012) indicated that two periods production are present in a horizontal well with multiple hydraulic frac stages. During the early period the interior of the reservoir (also referred to as the stimulated reservoir volume) contributes most of the production. The production from exterior part of the reservoir becomes more significant during the latter part of the production. Figure 2 illustrate the drainage area and horizontal well configuration utilized for the simulation runs. The interior of the reservoir is illustrated by a $4000 \times 1000 \mathrm{ft}^{2}$ rectangular drainage area while theexterior part of the reservoir $4000 \times 2000 \mathrm{ft}^{2}$ rectangular drainage area. Since the objective is to study the long term production performance in this study, the focus will be on the $4000 \times 2000 \mathrm{ft}^{2}$ rectangular drainage area.

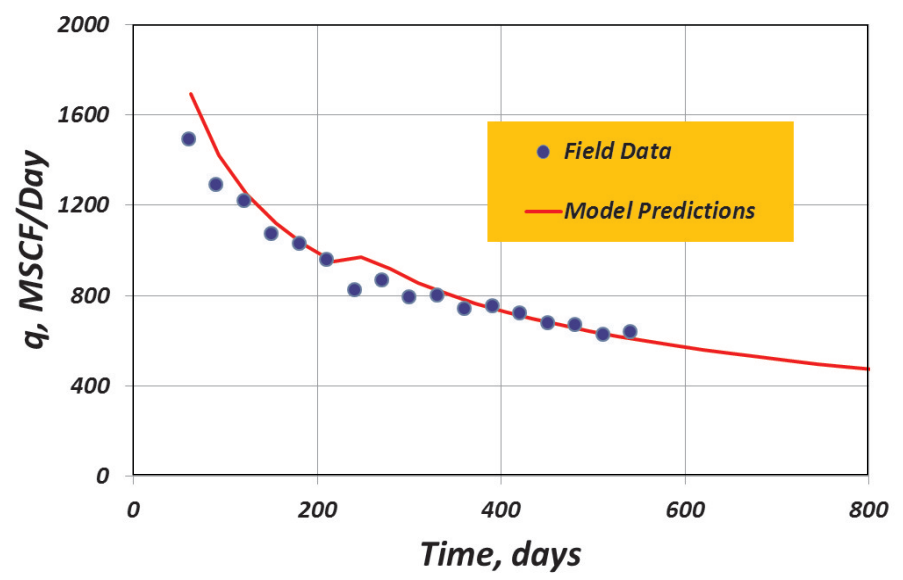

Fig. 1. Production History Matching for Horizontal Marcellus Shale Well in WV 
Table 1

Basic Model Parameters

\begin{tabular}{|l|c|}
\hline \multicolumn{2}{|c|}{ Reservoir Parameters } \\
\hline Initial Reservoir Pressure, psia & 3000 \\
\hline $\mathrm{P}_{\mathrm{wf}}, \mathrm{psia}$ & 500 \\
\hline Depth, $\mathrm{ft}$ & 7000 \\
\hline Thickness, $\mathrm{ft}$ & 75 \\
\hline Fissure Porosity, fraction & 0.005 \\
\hline Matrix Porosity, fraction & 0.05 \\
\hline Fissure Permeability, $\mathrm{i}, \mathrm{j}, \mathrm{k}, \mathrm{md}$ & $0.002,0.002,0.0002$ \\
\hline Matrix Permeability, $\mathrm{i}, \mathrm{j}, \mathrm{k}, \mathrm{md}$ & $0.0004,0.0004,0.00004$ \\
\hline Fracture Spacing, $\mathrm{s}, 1 / \mathrm{ft}^{2}$ & 0.073 \\
\hline Water saturation, fraction & 0.15 \\
\hline \multicolumn{1}{|c|}{ Hydraulic Fractures Properties } \\
\hline Half length, $\mathrm{ft}$ & 500 \\
\hline Width, in & 0.01 \\
\hline Top of fracture, $\mathrm{ft}$ & 7000 \\
\hline Bottom of Fracture & 7075 \\
\hline Permeability, md & 2000 \\
\hline Porosity, fraction & 0.2 \\
\hline & \\
\hline Diffusion Coefficient, $\mathrm{ft}{ }^{2} / \mathrm{day}$ & 1 \\
\hline Sorption Time, day & 62 \\
\hline Langmuir Pressure, $\mathrm{psia}$ & 635 \\
\hline Langmuir Concentration, SCF/ton & 89 \\
\hline
\end{tabular}

$4000 \mathrm{ft}$.

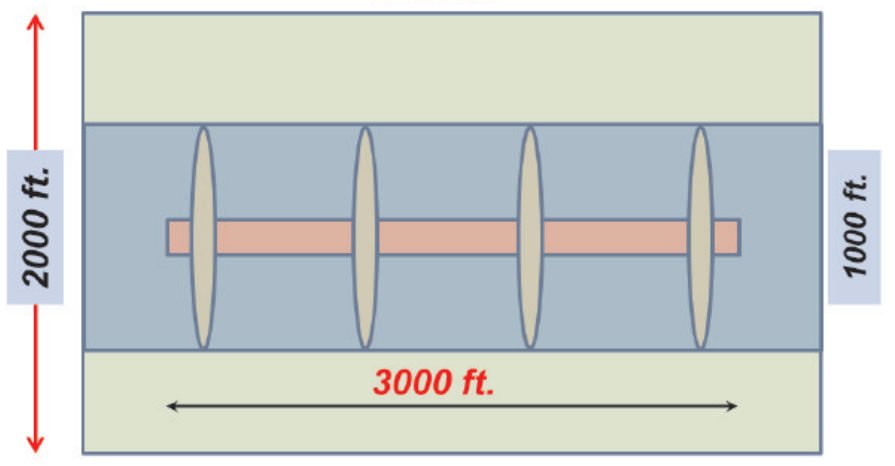

Fig. 2. Reservoir and Wellbore Configuration in the base Model with 4 Frac Stages 


\section{Long Term Production Prediction}

The model was utilized to generate the production profile with a constant wellbore pressure for a 30-year period for all the simulation runs. Three cases were considered to investigate the impact of the number of the hydraulic fracturing stages. They included 4 stages (1000-ft spacing), 7 stages (500-ft spacing), and 13 stages (250-ft spacing). To illustrate the production from the interior part of the reservoir, the production profile for $4000 \times 1000 \mathrm{ft}^{2}$ rectangular drainage area was also generated. Figure 3 compares the production from $4000 \times 1000$ and $4000 \times 2000 \mathrm{ft}^{2}$ drainage areas. Figure 4 illustrate the production rates from $4000 \times 2000 \mathrm{ft}^{2}$ area for different number of stages. To evaluate the impact of the adsorbed gas on production, the production profiles were also generated by excluding the adsorbed gas. Figure 5 compares the production profiles with and without adsorbed gas. Figure 6 illustrate the desorbed gas production.

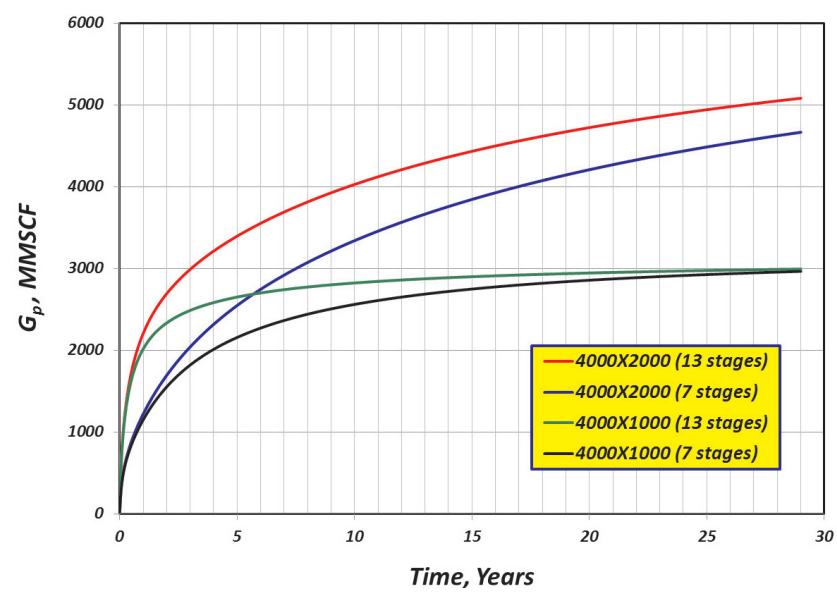

Fig. 3. Effect of Areas and Number of Stages on Production

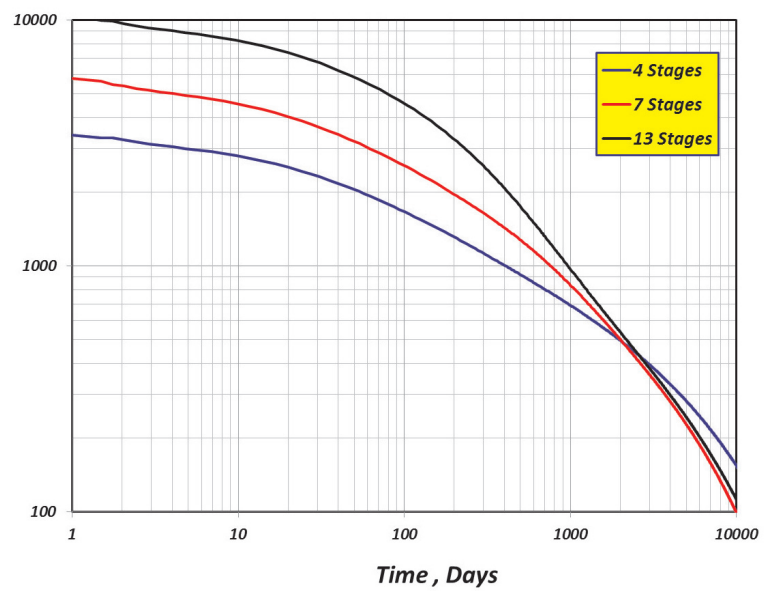

Fig. 4. Effect of Number of Stages on Production Rates $\left(4000 \times 2000 \mathrm{ft}^{2}\right)$ 


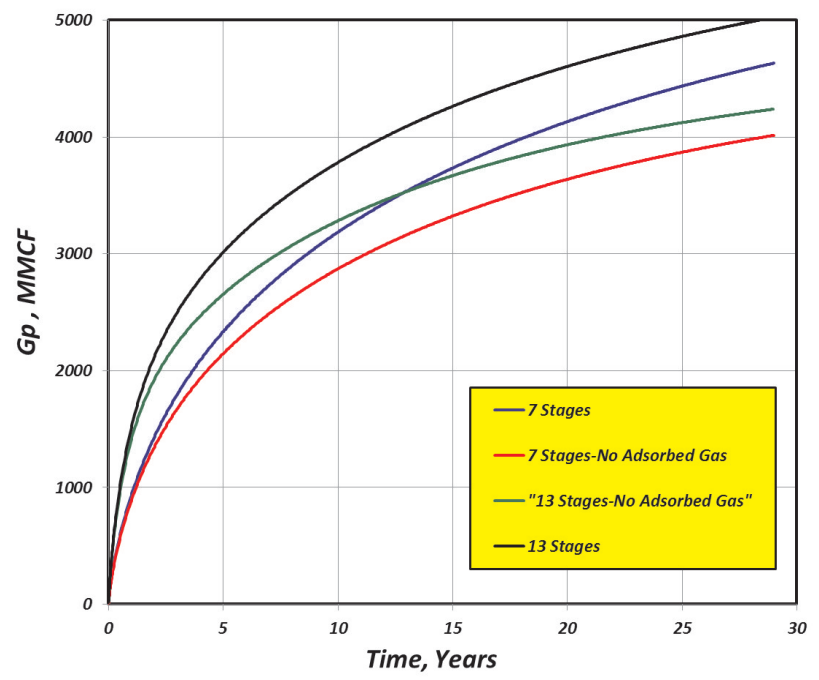

Fig. 5. Impact of Desorption on Production

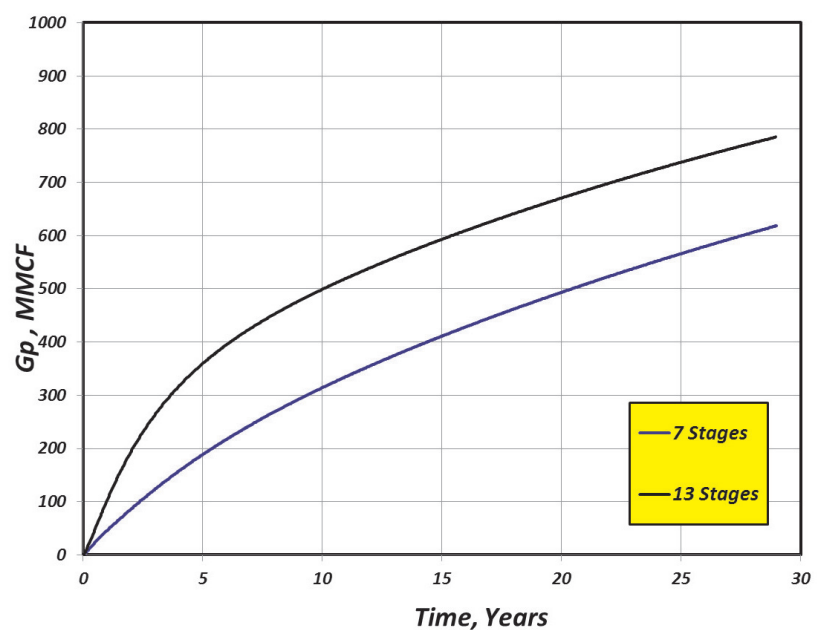

Fig. 6. Desorbed Gas Production

\section{Production Decline Behavior Analysis}

To develop a better understanding of the production performance and to provide a predictive tool, production decline analysis were performed on the simulated production profiles for horizontal wells with multiple hydraulic fracture stages. To accomplish this, the production history was divided in several periods and each period was matched with a separate hyperbolic decline curves. The decline curve parameters, $D_{i}$ and $b$, were estimated for each period. Table 2 summarizes the results of the analysis. 
Table 2

Results of the Decline Curve Analysis

\begin{tabular}{|c|c|c|c|c|}
\hline $\begin{array}{c}\text { Number } \\
\text { of Stages }\end{array}$ & Period, Years & $\boldsymbol{b}$ and $\boldsymbol{D i}$ & $\begin{array}{c}\text { Period, } \\
\text { Years }\end{array}$ & $\boldsymbol{b}$ and $\boldsymbol{D i}$ \\
\hline 4 & $2-7$ & $2,2.4$ & $14-30$ & $1,0.64$ \\
\hline 7 & $0.5-2$ & 2,11 & $6-24$ & $1,0.78$ \\
\hline 13 & $0.2-0.5$ & 2,53 & $2-20$ & $1,1.60$ \\
\hline
\end{tabular}

\section{DISCUSSION}

Inspection of the Figure 4 reveals no significant difference between production from $4000 \times 1000$ and $4000 \times 2000 \mathrm{ft}^{2}$ areas for the first 3 years. This suggests that during this period the production is primarily originates from the interior of the reservoir. As a result, the characteristics of the reservoir interior (stimulated reservoir volume) have a significant impact on production during this early period. These characteristics include the number; the location, and the half-length of hydraulic fractures (Belyadi A. et al. 2012). Furthermore, the production profiles, after 5 years, for 7 and 13 stages in $4000 \times 2000 \mathrm{ft}^{2}$ case are almost parallel. This suggests that the number of frac stages does not significantly impact the production from the exterior of the reservoir. However, the characteristics the reservoir exterior, mainly fissure permeability and porosity, can have impact on the late production.

Inspection of the Figure 6 reveals that the desorbed gas production significantly increases during the first 5 years for 13 stages as compare to 7 stages. As was concluded earlier, most of the production during this period originates from the interior of the reservoir. Therefore, the characteristics of the reservoir interior (stimulated reservoir volume) also control the desorbed gas production during this period. Furthermore, the desorbed gas production profiles after 5 years, for 7 and 13 stages are almost parallel. This suggests that the desorbed gas production during this period is controlled primarily by the characteristics of the reservoir exterior.

Inspection of the Figure 4 reveals that several flow periods may be present. The very early period (10-70 days) reflects nearly a slope of -4 which is the indication of the bilinear flow. The next flow period, with the slope of nearly -2 which is the indication of the linear flow, appears at different time periods for different number of stages. The linear flow for 4 stages (500-2500 days) appears to start later and last somewhat longer than for 7 stages (200-900 days). The linear flow regime for 13 stages (100-250 days) appears to be much shorter. Finally, the latter part of the all production profiles approach slope of -1 due to the boundary effects. This period appears to occur earlier as the number of frac stages is increased.

To achieve a better understanding of the production behavior, diagnostic plots were prepared to investigate the presence and duration of the various flow regimes. To prepare 
the diagnostic plots, the derivative of the inverse of the flow rate (1/q) was plotted versus time on log-log scale as illustrated in Figure 7. Inspection of the Figure 7 reveals that the early period is not characterized by slope of $-1 / 4$ and therefore it is not bi-linear flow. In fact, it is the radial-linear flow which is within the hydraulic fracture plane. Due to high conductivity of the fracture, this flow has similar characteristics as the wellbore storage. It should be noted that the production over this period is generally over-predicted by the model. There are a number of reasons for this. First, the model assumes that the entire propped fracture volume was completely filled by free gas that would be produced almost instantaneously when the well is brought on production. Furthermore, the model assumes that the horizontal wellbore and the perforations are clear of any fluid. In actuality, there could be some fracturing fluid (water) remaining in the hydraulic fracture, perforations, or the wellbore which interfere with the production. Additionally, the early production could be impacted by the pipeline or other flow restrictions.

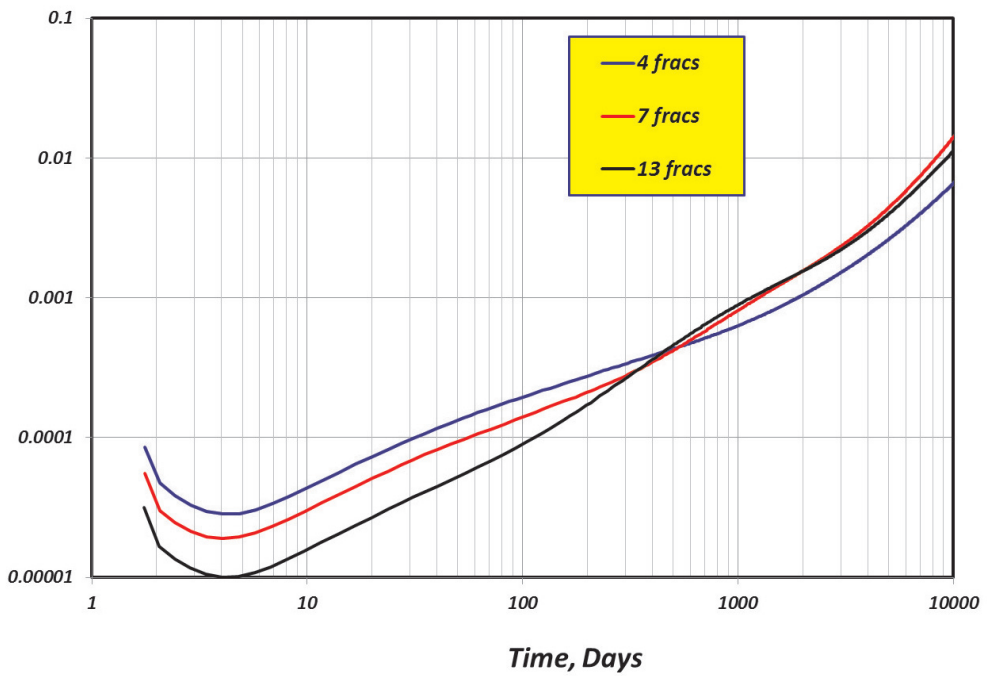

Fig. 7. Diagnostic Plot for Different Number of Stages

The linear flow, on the other hand, can be clearly identified for both the 4 stages and 7 stages with slope of $1 / 2$ on Figure 7 . However, slope of $1 / 2$ does not appear to be present in the case of 13 stages. This is due to earlier onset of boundary effects which mask the linear flow period. Inspection of the Figure 6 reveals that the desorbed gas production could also impact the appearance of the linear flow for the 13 stages. Finally, the latter production periods are characterized by slope of nearly 1 . It is interesting to note that two separate periods with the slope of 1 appear to be present for 13 frac stages. This may be due to presence of the different boundaries. The first is due the interference with the other fractures and second is due to the impact of the reservoir exterior. With fewer hydraulic fracture stages, the interference with other fractures occurs later and may not be distinguishable from the impact of reservoir exterior. 
The results of decline curve analysis indicate that a single value for the decline exponent (b)cannot be usedto characterize the entire production period. This is primarily due to the fact that the transient flow dominates the initial production for a relatively long time since the formation permeability is ultra-low. It is therefore important to not use the conventional decline analysis to predict the future production or reserves based on the early production data. This will lead to significant over-prediction of the production. The results given in Table 2 indicate that the early period is characterized by $b=2$, which reflect the transient linear flow. The duration of the linear flow decreases with increase in the number of stages. The decline behavior during the latter part of the production is characterized by $\mathrm{b}=1$, which is can be interpreted asthe harmonic decline.

\section{CONCLUSIONS}

For horizontal wells with multiple hydraulic fracture stages completed in ultra-low permeability formations the following conclusions were reached:

1. The early production behavior is controlled by the characteristics of the reservoir interior (stimulated reservoir volume) including the number; the location, and the halflength of hydraulic fractures.

2. The late production is controlled by the characteristics of the reservoir exterior, mainly fissure permeability and porosity.

3. The gas desorption is also influenced by the characteristics of the reservoir interior during early production and by the characteristics of the reservoir exterior during the latter production period.

4. The early production period is characterized by linear flow.

5. The duration of the linear flow decreases with increase in the number of stages.

6. The late production period is characterized by harmonic decline.

7. The interference with the other hydraulic fractures and the reservoir exterior can cause boundary effects.

8. Conventional decline analysis based on the early production data can lead to significant over-prediction of the future production rates or reserves.

\section{REFERENCES}

[1] Belyadi A., Aminian K., Ameri S.: Production Performance of the Multiply Fractured Horizontal Wells. SPE 153894, SPE Western Regional Conference, Bakersfield, California, March 2012.

[2] Brown M., Ozkan E., Raghavan R., Kazemi H. (2009): Practical solutions for pressure transient responses of fractured horizontal wells in unconventional reservoirs. SPE 125043, 2009 SPE Annual Technical Conference and Exhibition, New Orleans, 4-7 October 2009. 
[3] Cipolla C.L., Lolon E.P., Erdle J.C., Tathed V. (2009a): Modeling Well Performance in Shale-Gas Reservoirs. SPE 125532, October 2009, Abu Dhabi, UAE.

[4] Cipolla C.L., Lolon E.P., Dzubin, B. (2009b): "Evaluating Stimulation Effectiveness in Unconventional Gas Reservoirs," SPE-124843, October 2009, New Orleans, Louisiana.

[5] Lu J., Zhu T., Tiab D. (2009): Pressure behavoir of horizontal wells in dual-porosity, dual-permeabilty naturally fractured reservoirs. SPE 120103, 2009 SPE Middle East Oil \& Gas Show and Conference, Bahrain, 15-18 March 2009.

[6] Rosa A.J., Cavalho R.S.: Transient pressure behavior of horizontal wells in naturally fracured reservoirs. SPE 18302. SPE Annual Technical Conference and Exhibition, Houston, October 1988.

[7] Ozkan E., Brown M., Raghavan R.,Kazemi H.: Comparison of fractured horizontalwell performance in conventional and unconventional reservoirs. SPE 121290, SPE Western Regional Meeting, San Jose California 24-26 March 2009.

[8] Warpinski N.R., Mayerhofer M.J., Vincent M.C., Cipolla C.L., Lolon E.P.: Stimulating Unconventional Reservoirs: Maximizing Network Growth While Optimizing Fracture Conductivity. SPE 114173, February 2008, Keystone, Colorado. 